\title{
PENGARUH LAYANAN KONSELING INDIVIDU DENGAN TEKNIK MODELLING UNTUK MENINGKATKAN MOTIVASI BELAJAR DI SMA NEGERI 1 TAMBAKBOYO
}

\author{
PRIHATININGTIA \\ SMA Negeri 1 Tambakboyo \\ prihatiningtia@gmail.com
}

\begin{abstract}
The purpose of this study was to determine the effect of the application of individual counseling services with modeling techniques to increase learning motivation at SMA Negeri 1 Tambakboyo. The research method used the experiment with one group pretest-posttest, namely experiment $=$ pretest-treatmen-posttest $(X=01-X 1-02)$. The data source used scores from students' questionnaires, interviews and observations. The results of data collection include the results of direct observations, field notes, results of interviews from subject teachers and closed questionnaires. This research procedure with pretest and posttest. While the treatments are carried out with individual counseling with modeling techniques. A symbolic modeling technique that tells / describes a successful tokok. And the counselee also knows the tokok. From the experience of this figure, it is hoped that it can increase the stimulus so that the learning motivation of students increases. The conclusion of this study is that individual counseling services with modeling techniques can improve students' learning motivation, namely no absent 24 class XII IPA 1 SMA Negeri 1 Tambakboyo.
\end{abstract}

\section{ABSTRAK}

Tujuan penelitian ini adalah untuk mengetahui pengaruh penerapan layanan konseling individu denganteknik modelling untuk meningkatkan motivasi belajar di SMA Negeri 1 Tambakboyo. Metode penelitian menggunakan experiment with one grup pretest- posttest yaitu experiment= pretest-treatmen-posttest $(\mathrm{X}=01-\mathrm{X} 1-\mathrm{O} 2)$. Sumber data menggunakan Skor hasil angket peserta didik, wawancara dan observasi. Hasil pengumpulan data meliputi hasil observasi langsung, catatan lapangan, hasil wawancara dari guru mata pelajaran dan angket tertutup. Prosedur penelitian ini dengan pretest dan posttes. Sedangkan treatmen yang dilakukan dengan konseling individu dengan teknik modelling. Teknik modelling dengan simbolik yang menceritakan/menjelaskan seorang tokok yang sukses. Dan konseli juga mengenal tokok tersebut. Dari pengalaman tokoh tersebut diharapkan dapat meningkatkan stimulus agar motivasi belajar peserta didik meningkat. Kesimpulan dari penelitian ini yaitu layanan konseling individu dengan teknik modelling dapat meningkatkan motivasi belajar peserta didik yaitu no absen 24 kelas XII IPA 1 SMA Negeri 1 Tambakboyo.

Cara mengutip: Prihatiningtia, P. (2020). Pengaruh Layanan Konseling Individu dengan Teknik Modelling untuk Meningkatkan Motivasi Belajar di SMA Negeri 1 Tambakboyo. Nusantara of Research : Jurnal Hasil-Hasil Penelitian Universitas Nusantara PGRI Kediri (e-Journal), 7(1), 49-56. https://doi.org/10.29407/nor.v7i1.15068

\section{PENDAHULUAN}

Pendidikan suatu hal penting bagi kemajuan suatu negara. Individu dengan kemauan yangtinggi memiliki masa depan yang sukses, berwawasan ke depan, suka hambatan, dan giat dalam belajar atau bekerja. Dalam meningkatkan hasil belajar peserta didik ada banyak 
teknik untuk mengembangkan motivasi dalam pembelajaran yaitu ucapan motivasi secara langsung, nilai $\mathrm{UH}$, memancing keingintahuan, memunculkan hal yang tidak terduga, stimulus dan respon, menunjukkan persaingan, menentukan tujuan, mencontohkan hal yang positif dalam belajar.

Adanya proses pembelajaran yang baru dikarenakan kondisi lingkungan yaitu adanya pandemi/ wabah penyakit covid 19. Maka dalam lingkungan pendidikan menerapkan pembelajaran jarak jauh (PJJ) atau pembelajaran melalui daring. PJJ yang dilakukan di SMA Negeri I Tambakboyo membuat motivasi belajar siswa menurun hal itu terlihat Ketika siswa sering terlambat mengumpulkan tugas, tidak mengerjakan tugas, tidak mengikuti pembelajaran daring.Ada salah satu peserta didik yang selalu mendapatkan nilai jelek saat $\mathrm{UH} / \mathrm{kuis}$ daring, cuek pada jadwal pembelajaran daring, mempunyai banyak alasan dalam pembelajaran daring. Satu peserta didik juga mengungkapakan banyak alasan-alasan tidak mengikuti pembelajaran daring. Alasan-alasan tersebut diantaranya lupa karena asyik berrnain dengan teman diruinah, membantu orang tua, ikut teman bekerja untuk mendapatkan uang dan malas atau segan dalam pembelajaran daring. Peserta didik kurang menyadari apa yang di lakukan akan berakibat fatal diantaranya mendapatkan nilai jelek dan dapat tidak naik kelas.

Bedasarkan hasil observasi pada tanggal 06 Agustus 2020 dari 6 kelas XII ada satu kelas yang mengalaini penurunan motivasi belajar yang rendah yaitu kelas XII IPA 1. Data selanjutnya adalah hasil wali kelas XII IPA 1 tanggal 10Agustus 2020 ada salah satu anak yang sangat sering tidak mengikuti pembelajaran daring. Kemudian untuk memperkuat data observasi dan laporan maka peneliti menyebarkan angket untuk mengetahui motivasi belajar kelas XII IPA 1 yang dilakukan pada tanggal 12 Agustus 2020 dan hasilnya ada satu anak yang sangat sering sekali tidak pernah mengikuti PJJ.

Menurut Sobur (2003) Motivasi adalah membangkitkan daya gerak atau menggerakan seseorang atau diri sendiri untuk berbuat sesuatu dalam rangka mencapai suatu kepuasan atau tujuan. Sedangkan belajar menurut Sobur (2003) adalah perubahan prilaku yang relatif tetap sebagai hasil dari pengalaman. Jadi motivasi dalam belajar adalah dorongan yang dimiliki individu untuk melakukan perubahan prilaku yang menimbulkan kegiatan dan arah belajar untuk mencapai tujuan yang dikehendaki sebagai hasil dari pengalaman. Menurut Sardiman (2007) ciri-ciri orang yang memiliki motivasi belajar adalah tekun menghadapi tugas, ulet menghadapi kesulitan belajar, menunjukkan minat terhadap masalah belajar, lebih senang belajar mandiri, cepat bosan pada tugas-tugas yang rutin, dapat mempertahankan pendapat, tidak mudah melepaskan hal yang diyakini serta senang mencari dan memecahkan soal-soal. Peserta didik jika memiliki motivasi yang rendah akan mendapatkan kerugian diantaranya tertinggal dalam pelajaran, tidak bisa mengerjakan soal dan mendapatkan nilai jelek. Dimyati dan Mudjiono (2009) menyatakan akan pentinnya motivasi dalam belajar adalah menyadarkan kedudukan awal belajar, proses dan akhir, menginformasikan tentang kekuatan dalam belajar, mengarahkan kegiatan belajar, membesarkan semangat belajar, serta menyadarkan tentang adanya perjalanan belajar dan kemudahan belajar yang bersinambungan.

Permasalahan diatas dapat disimpulkan motivasi belajar peserta didik menurun pada PJJa tau belajar melalui daring yang terjadi di SMA Negeri Tambakboyo. Motivasi 
belajartidakmenjadi tanggung jawab guru mata pelajaran saja tetapi juga tanggung jawab guru bimbingan dan konselingyaitu memberikan pelayanan bimnbingan dan konseling. Pelayanan bimbingan dan konselingyangdiberikan di sekolah meliputi layanan dasar BK dan layanan resposif BK. Peneliti tertarik untuk melakukan penelitian menggunakan layanan Konseling Individu. Tujuan layanan konseling individu yaitu membantu mengatasi permasalahan yang dialami dan mengoptimalkan potensinya.

Penelitian terdahulu yang dilakukan oleh Fina Melati (2011) di kelas RSBI di SMP Negeri 3 Batang tentang upaya meningkatkan motivasi belajar melalui layanan penguasaan konten dengan teknik permainan pada siswa kelas VII RSBI di SMP Negeri 3 Batang dengan hasil sebelum perlakuan $62,37 \%$ sedangakan setelah diberi perlakuan $71,13 \%$ hal ini adanya perubahan. Penelitian tersebut dilakukan dengan responden dalam satu kelas. Sedangkan penelitian yang saya lakukan hanya satu peserta didik oleh karena itu peneliti menggunakan layanan konseling individu dengan teknik modelling. Teknik modelling dipilih karena dalam proses belajar salah satu cara yang efektif agar cepat memahami suatu hal yang baru dengan cara modelling atau percontohan. Layanan konseling dengan teknik modelling menggunaka cerita suatu tokoh yang sukses dapat membantu peserta didik untuk merangsang semangat belajar karena peserta didik diajak secara langsung melihat model atau seseorang yang dapat menjadi contoh meningkatkan motivasi belajar. Maka hal ini dapat menjadi sebuah judul PTBK "Pengaruh Layanan Konseling IndividudenganTeknik Modelling untuk Meningkatkan Motivasi Belajar di SMA Negeri 1 Tambakboyo".

\section{METODE}

Metode penelitian dengan Experiment With One Grup Pretest-Postes Desaign. Metode ini di aplikasikan atas pemberian treatment $(X)$ pada konseli. Konseli yangtelah pretest(01) selanjutnya diberikan perlakuan atau treatment (X1). Ketikatreatmentsudah diberikan kepada konseli, maka selanjutnya konseli akan melaksanakan posttest(O2). Hasil konseli yang telah diberikan pretest dan posttest akan dikomparasikan dengan tujuan agar peneliti memiliki data tentang progress dari konseli (Sugiono, 2010). Sedangkan treatment yang di berikan dengan menggunakan teori Kemmis dan McTaggart (dalam Hidayat Dede Rahmat dan Aip Badrujman, 2012: 12), PTK adalah kegiatan yang memiliki empat langkah penelitian, yakni (1) perencanaan, tindakan, pengamatan, dan refleksi. Penelitian tindakan kelas adalah penelitian dengan pencermatan terhadap proses belajar berupa tindakan, dan terjadi dalam sebuah kelas secara bersama (Arikunto dkk, 2014:3).

Tabel 1. Experiment desing with one grub pretes-posttest

\begin{tabular}{llll}
\hline Group & Pretest & Treatment & Posttest \\
\hline Experiment & O1 & X1 & O2 \\
\hline Keterangan: & & \\
O1: Kondisi awal konseli sebelum pemberian layanan konseling individu & \\
X1: Treatment konseling individu & & \\
O2: Kondisi setelah proses layanan konseling individu & &
\end{tabular}

Proses penelitian ini menggunakan layanan konseling individu dengan teknik modelling. Hal pertama yang dilakukan adalah perencanaan dengan menyusun langkahlangkah kemudian melakukan koordinasi untuk menyusun program kegiatan, serta menyusun 
jadwal pelaksanaan. Peneliti mempersiapkan tokoh, sarana dan prasarana yang diperlukan dalam pelaksanaan, membuat instrurnen, pedoman wawancara, observasi dan pedoman penilaian peserta didik.

Tempat penelitian di SMA Negeri 1 Tambakboyo Kecamatan Tambakboyo, Kabupaten Tuban. Dilaksanakan pada semester gasal tahun ajaran 2020/202I. Pemilihan sebagai lokasi pelaksanaan penelitian dengan beberapa masukkan yaitu saat proses pembelajaran daring ada satu peserta didik yang tidak mengikuti, hasil UH daring jelek, disekolah tersebut tempat saya bekerja, dan pihak sekolah sangat mendukung dilaksanakannya penelitian ini untuk mendapatkan hasil belajar pesertadidik yang maksimal.Subjek penelitian adalah peserta didik kelas XII IPA 1 SMA Negeri 1 Tambakboyo Kecamatan Tambakboyo.Alasan peneliti memilih kelas XII IPA 1 sebagai subjek penelitian bedasarkan pada hasil observasi, interview dengan guru dengan jumlah peserta didik 34. Untuk mendapatkan konseli atau peserta didik yang tepat mendapatkan layanan konseling individu maka peneliti menggunakan angket tertutup sebagai pretes. Dari angket tersebut diambil yang mempunyai motivasi belajar yang sangat rendah.

Tabel 2. Pengkategorian Tingkat Motivasi Belajar

\begin{tabular}{cc}
\hline Pengkategorian motivasi belajar & Kategori \\
\hline $8-10$ & Tinggi \\
$4-7$ & Sedang \\
$0-3$ & Rendah \\
\hline
\end{tabular}

\section{HASIL}

Hasil dari observasi langsung dan interview dengan guru mata pelajran yang dilakukan pada bulan agustus di peroleh informasi peserta didik sering terlambat mengerjakan tugas dalam pembelajran daring, tidak mengumpulkan tugas dalam pembelajaran daring, peserta didik mendapatkan nilai UH jelek saat pembelajaran daring, dan tidak tepat waktu dalam pembelajarandaring. Adapun hasil data tersebut diambil dari skor hasil angket peserta didik.

Penelitian ini dilakukan pada peserta didik dengan no absen 24 XII IPA 1 SMA negeri 1 Tambakboyo. Dengan menggunakan konseling individu dengan teknik modellinguntuk meningkatkan Motivasi Belajar peserta didik. Data studi awal yang diperoleh dari observasi dengan guru mata pelajaran diperoleh penjelasan bahwa ada satu peserta didik yangsering tidak mengikuti pembelajaran daring. Hal itu dapat dilihat dari kesehariannya yaitu dengan tidak mengumpulkan tugas, terlambat mengumpulkan tugas dan mendapatkan nilai jelek saat UH daring. Untuk menentukan beberapa rendah motivasi belajar pesena didik tersebut, peneliti melakukan pengamatan dalam pembelajaran melalui jaringan kelas XII IPA 1 yang menjadi obyek penelitian. Peneliti menggunakan angket dengan jumlah item 10 pernyataan. Angket tersebut diedarkan pada hari Rabu, 12 Agustus 2020 dengan menggunakan googel fomulir sebagai pretest. https://forms.gle/UhroVRpBg7FUFrYJ6. 


\section{Hasil Pretes}

Tabel. 3 Hasil Observasi motivasi belajar peserta didik pretest kelas XII IPA 1 SMA Negeri 1 Tambakboyo

\begin{tabular}{|c|c|c|}
\hline No absen & Hasil pretes & Motivasi belajar \\
\hline 1 & 6 & Sedang \\
\hline 2 & 10 & Tinggi \\
\hline 3 & 4 & Sedang \\
\hline 4 & 9 & Tinggi \\
\hline 5 & 7 & Sedang \\
\hline 6 & 10 & Tinggi \\
\hline 7 & 9 & Tinggi \\
\hline 8 & 7 & Sedang \\
\hline 9 & 8 & Tinggi \\
\hline 10 & 9 & Tinggi \\
\hline 11 & 7 & Sedang \\
\hline 12 & 10 & Tinggi \\
\hline 13 & 9 & Tinggi \\
\hline 14 & 8 & Tinggi \\
\hline 15 & 6 & Sedang \\
\hline 16 & 10 & Tinggi \\
\hline 17 & 7 & Sedang \\
\hline 18 & 10 & Tinggi \\
\hline 19 & 9 & Tinggi \\
\hline 20 & 10 & Tinggi \\
\hline 21 & 10 & Tinggi \\
\hline 22 & 9 & Tinggi \\
\hline 23 & 7 & Sedang \\
\hline 24 & 2 & Rendah \\
\hline 25 & 8 & Tinggi \\
\hline 26 & 9 & Tinggi \\
\hline 27 & 10 & Tinggi \\
\hline 28 & 8 & Tinggi \\
\hline 29 & 7 & Sedang \\
\hline 30 & 6 & Sedang \\
\hline 31 & 9 & Tinggi \\
\hline 32 & 8 & Tinggi \\
\hline 33 & 9 & Tinggi \\
\hline 34 & 10 & Tinggi \\
\hline Rata2 & $277: 34=8,1$ & Tinggi \\
\hline
\end{tabular}

Dari hasil pengamatan yang dilakukan peneliti dengan mengguan angket dapat diperoleh data tertinggi adalah 10 dan skor terendah 0 . Dari data diperoleh skor rata-rata motivasi belajar adalah 8,1 ( tinggi ). Ada satu peserta didik yang termasuk dalam kategori rendah, 10 kategori sedang, dan 23 yang berkategori tinggi. Permasalahan yang dihadapi adalah satu peserta didik yang mempunyai motivasi belajar paling rendah yaitu peserta didik dengan no absen 24 dengan skor 2 . Untuk mengatasi permasalahan tersebut, peneliti berusaha memberi layanan konseling individu menggunakan strategi behaviorisme dengan teknik modelling. Layanan individu ini dipilih karena dapat berinteraksi secara langsung dengan peserta didik sehingga akan meningkatkan motivasi belajar dalam kondisi lingkungan yang ada. Pelaksanaan layanan konseling individu ada satu kali pertemuan yaitu hari Sabtu tanggal 18 
Agustus 2020. Proses layanan ini menggunakan via WA VC karena dalam SMA Negeri 1 Tambakboyo menerapkan pembelajaran daring. Dari hasil layanan individu ada perubahan sikap yang dilakukan peserta didik. Perubahan itu meliputi keikut sertaan peserta didik dalam pembelajaran daring. Hal ini di dapat dari hasil wawancara dan observasi pada tanggal 25 Agustus 2020 dengan wali kelas dan guru mata pelajaran. Hasil wawancara dan observasi setelah dilakukan proses layanan individu kepada wali kelas dan guru mata pelajaran didapat data: 1) Konseli sudah mengikuti pembelajaran daring; 2) Konseli mengerjakan tugas dan mengumulkan tepat waktu; 3) Konseli dapat mengerjakan tugas dengan mandiri

Tabel. 4 Motivasi belajar Hasil pretest dan hasil posttest

\begin{tabular}{lc} 
Keterangan & Hasil \\
\hline Pretest & 2 \\
Postest & 8 \\
\hline
\end{tabular}

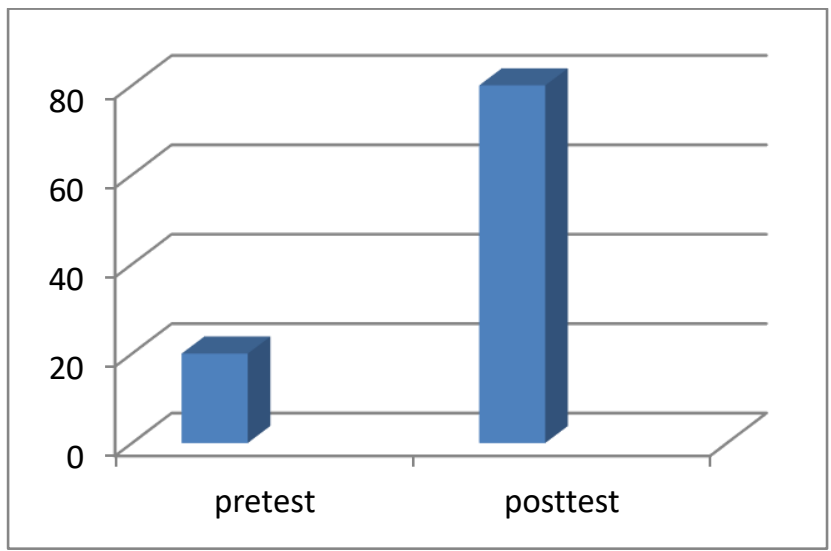

\section{PEMBAHASAN}

Gambar 1. Grafik perbandingan hasil pretest dan hasil posttes

Data awal untuk menentukan konseli peneliti mendapat laporan dari wali kepas dan guru mata pelajaran. Dari sini peneliti bergerak mencari permasalah yang dialami konseli. Peneliti melakukan observasi langsung, wawancara dari guru mata pelajaran dan wali kelas serta menyebarkan angket. Hasil dari pengisian angket secara tidak langs ung menjadi data awal konseli yang akan dituju. Berdasarkan analisis data awal di kelas XII IPA 1 di SMA Negeri 1 Tambakboyo terdapat satu peserta didik yang tidak pernah mengikuti pembelajaran daring atau KBM daring. Banyak alasan untuk tidak mengikuti KBM daring diantaranya lupa karena asyik bermain dengan teman dirumah, membantu orang tua, ikut teman bekerja untuk mendapatkan uang dan malas atau segan dalam pembelajaran daring karena sulit. Pesertadidik tersebut adalah kelas XII IPA 1 di SMA Negeri 1 Tambakboyo dengan No absen 24. Peneliti bertujuan ingin membantu permasalahan peserta didik agar tidak berakibat fatal yaitu tidak mendapatkan nilai di rapot.

Dalam proses konseling individu dengan teknik modeliling yang di berikan kepada konseli yaitu dengan menceritakan seorang tokok yang sukses. Kesuksesan di dalam tokoh tersebut dengan proses belajar yang panjang. Motivasi yang dimiliki dalam tokoh tersebut sangat besar walaupun banyak rintangan yang menghalanginya. Setelah proses konseling individu konserlo memberikan waktu selama 10 hari untuk dilakukan observasi. Apakah prilaku konseli berubah atau tidak. Dan dilakukannya posttest untuk mengetahui hasil dari treatmen yang diberikan. Hasil pengamatan yang dilakukan peneliti setelah proses konseling individu 
selama satu minggu prilaku konseli mengalami perubahan. Perubahan prilaku yang dilakukan adalah dengan mengikuti pembelajaran daring dan mengerjakan tugas tepat waktu.

Dari hasil analisis data di atas tentang perkembangan keadaan konseli atau peserta didik pada prestest dan postest setelah dilakukan treatment dan dilakukan perbandingan tersebut mengalami peningkatan atau perubahan yang cukup signifikan yaitu hasil pretest $20 \%$ sedangkan hasil posttes $80 \%$. Hal tersebut didukung dengan gambaran grafik data yang menunjukan perubahan yang cukup bagus pada perserta didik atau konseli. Dari hasil tersebut bisa dikatakan penggunaan konseling individu dengan teknik modelling dapat meningkatkan motivasi belajar.Tentunya pemberian treatment masih bisa dilakukan secara berkala kepada konseli yang bersangkutan. Dengan selalu mengontrol atau memantau peserta didik tersebut agar peserta didik atau konseli tidak menurun kernbali.

Penelitian yang dilakukan oleh Fina Melati (2011) di kelas RSBI di SMP Negeri 3 Batang tentang upaya meningkatkan motivasi belajar melalui layanan penguasaan konten dengan teknik permainan pada siswa kelas VII RSBI di SMP Negeri 3 Batang. Penelitian yang dilakukan oleh Cristina Nelawati (2017) di kelas VIII H SMP Negeri 15 Yogyakarta tentang upaya meningkatkan motivasi belajar siswa SMP jalur kartu menuju sejahtera melalui layanan bimbingan kelompok dengan metode grub dynamis pada siswa kelas VIII H dan dapat membuktikan metode grub dynamis dapat meningkatkan motivasi belajar siswa VIII H SMP Negeri 15 Yogyakarta. Penelitian yang dilakukan oleh Tri Wirda Hayani( 2008) 50 remaja putri tentang hubungan antara medelling dengan perilaku membeli pakaian pada remaja putri. Penelitian dilakukan oleh Hikmah fitriati (2012) pada siswa kelas IV SD Negeri 2 Karang Jati Banjarnegara tentang penerapan metode modelling untuk meningkatkan hasil belajar materi membuat kerajinan dari kertas.

\section{KESIMPULAN DAN SARAN}

Penggunaan teknik modelling dalam mengatasi motivasi belajar yang dilakukan dengan konsling individu dapat meningkatkan motivasi belajar. Prilaku konseli yang mengalami perubahan terus meningkat. Dari hasil pemaparan dan penjelasan penelitian bimbingan dan konseling di atas maka penulis dapat menyimpulkan bahwa layanan konseling individu dengan teknik modelling dapat meningkatkan motivasi belajar peserta didik atau konseli di SMA negeri 1 Tambakboyo.

Tentunya hasil dari penelitian ini masih sangat jauh dari kata sempurna maka dari itu saran untuk semua pihak adalah terus mengerbangkan dan mengupdate kemampuan dalam melakukan dan menggunakan teknik dan teori konseling dalam rnembantu menyelsaikan masalah konseli atau pesena didik. pemberian treatment masih bisa dilakukan secara berkala kepada peserta didik yang bersangkutan. Dikawatikan peserta didik mengalami penurunan motivasi belajar kembali.

\section{DAFTAR RUJUKAN}

Arikunto, S. (2014). Prosedur Penelitian (Suatu Pendekatan Praktik). Jakarta: RinekaCipta

Dimyati dan Mudjiono.2002. Belajar dan Pembelajaran. Jakarta: Rineka Cipta

Hidayat, Dede Rahmat \& Aip Badrujaman. (2012). Penelitian Tindakan dalam Bimbingan danKonseling. Jakarta :PT. Indeks.

Sardiman, A.M. 2007. Interaksi dan Motivasi Belajar Mengajar. Jakarta: Rajawali Grafindo Persada 
Sobur, Alex. 2003. Psikologi Umum. Bandung: Pustaka Setia

Sugiono. 2010. Metode Penelitian Pendidikan Kuantitatif, kualitatif dan R\&D. Bandung: Alfabeta.

Melati, Fina (2011). Upaya Meningkatkan Motivasi Belajar Melalui Layanan Penguasaan Konten Dengan Teknik Permainan Pada Siswa Kelas VII RSBI Di SMP Negeri 3 Batang. Skripsi. Universitas Negeri Semarang

Nelawati, Cristina (2017). Upaya Meningkatkan Motivasi Belajar Siswa SMP Jalur Kartu Menuju Sejahtera Melalui Layanan Bimbingan Kelompok Dengan Metode Grub Dynamis Pada Siswa Kelas VIII H Dan Dapat Membuktikan Metode Grub Dynamis Dapat Meningkatkan Motivasi Belajar Siswa VIII H SMP Negeri 15 Yogyakarta. Sripsi. Universitas Sanata Darma Yogyakarta

Hayani, Tri Wirda (2008). Hubungan Antara Medelling Dengan Perilaku Membeli Pakaian Pada Remaja Putri.Universitas Islam Negeri Syarif Hidayatullah

Fitriati, Hikmah (2012). tentang penerapan metode modelling untuk meningkatkan hasil belajar materi membuat kerajinan dari kertas pada siswa kelas IV SD Negeri 2 Karang Jati Banjarnegara. Universitas Negeri Semarang 